\title{
Effect of Biodiesel Concentration on Corrosion of Carbon Steel by Serratia marcescens
}

\author{
Yustina M Pusparizkita ${ }^{1}$, Tjandra Setiadi ${ }^{1}$, and Ardiyan Harimawan ${ }^{1, *}$ \\ ${ }^{1}$ Institut Teknologi Bandung, Department of Chemical Engineering, 40132 Bandung, Indonesia
}

\begin{abstract}
Biodiesel come into being used as an alternative source of energy as the diminishing of petroleum reserves. This fuel is typically stored in tanks that are commonly made from carbon steel, which is easily corroded by microorganisms. Recent studies have shown that bacteria aside from SRB may also be involved in corrosion. Therefore, this research was aimed to evaluate the effect of biodiesel concentration $(15 \%, 20 \%$ and $30 \% \mathrm{v} / \mathrm{v})$ mixed in diesel oil on the corrosion of carbon steel by $S$. marcescens that dominate biocorrosion on hydrocarbon products. In this study, the corrosion process was investigated by evaluation of biofilm morphology and composition, the rate of corrosion and the corrosion product of carbon steel which was exposed in the mixture of hydrocarbons and the presence of $S$. marcescens. It can be concluded that higher concentration of biodiesel in diesel oil leads to higher growth of bacteria in the biofilm and higher corrosion rate.
\end{abstract}

\section{INTRODUCTION}

In response to the petroleum crisis, the existence of biofuels as alternative energy sources are necessary to anticipate the depletion of petroleum fuels. Moreover, Indonesia has natural resources that can be potentially exploited for the production and exported biofuels as biodiesel. In this case, biodiesel can be produced from palm oil, soybeans, and jatropha curcas. Additionally, they are commonly planted and have potential to be developed in Indonesia. Due to the increasing demand for diesel oil in the transportation and industrial sectors, correspondingly, the biodiesel mixed with diesel fuel in Indonesia continues to be investigated. The Indonesian government through Permen ESDM No. 122015 expects the use of biodiesel as a mixture of up to $30 \%$ of total fuel demand, which can be achieved by 2025 .

Petroleum products and biofuels are usually stored in a large tank made of carbon steel. Carbon steel is more widely used by the industry as a construction material as well as material for storage tanks. The use of carbon steel in term of price is due to carbon steel is lower cost than other metals such as stainless steel [1]. However, the carbon steel has a susceptibility to corrosion by microorganisms. Several studies have demonstrated a significant negative impact of biocorrosion occurring in carbon steel. Microbiologically influenced corrosion (MIC) and biofilm may cause pitting because sulphides resulting from SRB metabolism settle on the surface of iron and forming iron sulphide (FeS) at oil field separator and offshore installation $[2,3]$. Furthermore, on the crude oil tank, SRB may form a biofilm in the form of a black layer on the bottom of the tank containing crude oil and fuel oil [4].
Petroleum products and biofuels are usually stored in large tanks, then pumped through pipes to be stored and or transported to smaller tanks. In the process of distribution, there is potential for contamination of microorganisms. Factors that contribute to the contamination of hydrocarbon products and the growth of microorganisms are climate, distribution system design, the chemical composition of fuels, methods, and effectiveness of cleaning as well as product quality control [5]. Contamination of microorganisms in products is very difficult to prevent because sterile conditions during transport and fuel storage can not be maintained. Moreover, microorganisms are commonly found in air, water, and soil [6]. The development of these microorganisms contributes to corrosion of the tank.

Corrosion in the tank may occur because microorganisms can degrade hydrocarbons as a source of nutrients. Also, biofuels are a suitable medium for the growth of microorganisms. Products generated through MIC metabolism in the form of extracellular polymeric substance (EPS), organic and inorganic acids will form biofilms that can change the condition of the surrounding environment and trigger corrosion. The corrosion reaction can run faster or slower in the presence of microorganisms as it affects the electron transfer process on the metal surface [1].

Biofilms are formed by the most common microorganism as survival strategies for allowing bacterial species to develop their own microenvironment as part of a defense, food supply and metabolic interactions [1]. Several types of bacteria can live simultaneously in biofilm such as bacteria that produce metabolic products that can support the growth of other

Corresponding author: ardiyan@che.itb.ac.id 
bacteria. The formation of microbial colonies begins with the interaction and attachment of single-cell bacteria on the metal surfaces coated with a thin film layer. Carbon steel is a type of metal that is easy to corrode because of the passive layer of iron oxide is a perfect surface for the attachment of microorganisms [1]. This process is called adhesion or attachment. While electrostatic interactions contribute to the attachment of microorganisms to the surface, the attachment process of the cell is influenced by EPS which causes the strong bonding between microbes to each other and the surface [2]. The bonds between microbes will be strengthened along with the joining of other bacteria (colonization) and accumulated, characterized by increasing the complexity biofilms formed [3]. The next process is early biofilm maturation stage. The ongoing process is the unification of all metabolic processes of colonized cells, including the use of substrates and nutrients in the medium [4] and each bacterium uniting its structure, function, and activity into the biofilm [5]. In this stage, there is a process of cleavage, enlargement, and maturation of polysaccharides which causes the colony to appear enlarged so that the thickness of the biofilm increases [1]. In the final phase, some bacteria will spread and colonize elsewhere [6].

Further, the most common microorganisms involved in the corrosion of the petroleum production system includes the anaerobic SRB [7]. However, the recent studies have shown that other types of bacteria may also be involved in biocorrosion [8-11]. The several species such as $S$. marcescens have the ability to degrade a variety of hydrocarbons [12]. Here, these species after Bacillus sp. dominate in the corrosion product of the napha piping transport [13].

With the increasing use of biodiesel mixed with diesel oil, it was necessary to examine the characteristics of carbon steel on biocorrosion including the ratio of the number of bacteria attached to the biofilm, the biofilm morphology and the rate of corrosion in biodiesel and diesel oil blends.

\section{Methods}

This research consisted of three main stages namely preparation, experimental and corrosion analysis to observed biocorrosion characteristics of carbon steel ST37 in a mixture of $15 \%, 20 \%$ and $30 \% \mathrm{v} / \mathrm{v}$ biodiesel produced from laboratory and diesel oil from Pertamina containing S. marcescens ATCC 27117.

\subsection{Preparation}

The preparation stage consisted of the culture stage, the test solution preparation, the preparation of metal and the reactor.

\subsubsection{Culture stage}

The growth medium used for $S$. marcescens was Bushnell Haas (BH). BH medium consisted of $\mathrm{MgSO}_{4}$ $0.2 \mathrm{~g} / \mathrm{L}, \mathrm{CaCl}_{2} 0.02 \mathrm{~g} / \mathrm{L}, \mathrm{KH}_{2} \mathrm{PO}_{4} 1 \mathrm{~g} / \mathrm{L}, \mathrm{K}_{2} \mathrm{HPO}_{4} 1 \mathrm{~g} / \mathrm{L}$, $\mathrm{NH}_{4} \mathrm{NO}_{3} 1 \mathrm{~g} / \mathrm{L}$ and $\mathrm{FeCl}_{3} 0.05 \mathrm{~g} / \mathrm{L}$. To increase the number of $S$. marcescens, these bacteria were cultured in a sterilized $\mathrm{BH}$ medium with a working volume of 100 $\mathrm{mL}$ until it enters a stationary growth stage. After entering the stationary phase, the acclimatization was done by taking $2 \mathrm{~mL}$ inoculated bacteria into $300 \mathrm{~mL}$ of $\mathrm{BH}$ medium and $1 \mathrm{~g}$ of sterilized diesel oil as a sole nutrition in an Erlenmeyer, which was then incubated with the temperature of $27^{\circ} \mathrm{C}$ and $200 \mathrm{rpm}$ for 30 days in a rotary shaker.

\subsubsection{Test solution preparation}

The hydrocarbon to be used as the immersion medium was filtered with CA filter membrane with a pore size of $0.45 \mu \mathrm{m}$ to remove impurities and microorganism that may be contained.

\subsubsection{Specimens and reactor preparation}

Specimen preparation followed several steps. According to ASTM G 31-72 standard, the specimen of carbon steel was cut into $1 \mathrm{~cm} \times 1 \mathrm{~cm}$. Based on ASTM G 1-81, the specimens were polished using 240-1200 grid abrasive paper and washed using water and ethanol to remove fat and impurities. Once clean, the specimens were dried and stored in a desiccator to keep it dry.

The soaking reactor and the hanging pole for specimens were made of glass, while the reactor cover was made of acrylic.

\subsection{Experimental}

Types of hydrocarbons which were used as a soaking medium are the mixture of diesel oil with $15 \%, 20 \%$ and $30 \%$ biodiesel as variations. Immersion process was done by hanging specimens in pole hangers made of glass and dipped in submersion glass reactor containing $10 \% \mathrm{v} / \mathrm{v}$ culture of $S$. marcescens. Volume of immersion working reactor is $800 \mathrm{ml}$. All submersion reactors kept sterile from outside influences that can be contaminated by sealing the reactor with wax. The reactor was then stored at the temperature of $25^{\circ} \mathrm{C}$ and under anaerobic condition for 10 days. At certain time intervals, the reactor was opened to pick up metal specimens and analysed the biofilms.

\subsection{Corrosion analysis}

Some analysis was done in this study including total plate count (TPC) method to analyse the bacterial colonies on biofilm, biofilm morphology using scanning electron microscopy (SEM) and gravimetric method 
refers to ASTM G1 to observe the corrosion rate and the influence of $S$. marcescens on corrosion. For each method of the analysis, two specimen replicas were assessed.

\section{Results}

\subsection{The growth of $S$. marcescens in biofilm}

By counting the number of bacterial colonies in the biofilm that are formed on the metal surface using TPC analysis, bacterial growth in a biofilm can be observed to determine the ability of $S$. marcescens to live in biofilms. The number of $S$. marcesccens colonies that live was calculated every two days during the immersion period to obtain a growth profile of $S$. marcesccens in the biofilm. The profile of $S$. marcescens colonies on the biofilms can be seen in Figure 1.

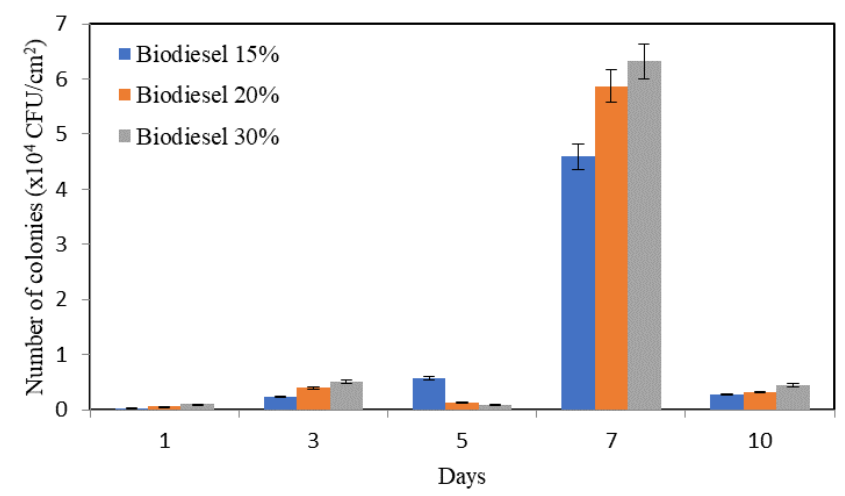

Fig. 1 The growth of $S$. marcescens in biofilm

At $15 \%$ biodiesel concentration, the number of bacterial colonies on the biofilm slowly grew from the first day and then increased significantly on the seventh day. On the tenth day, the number of colonies declined drastically. While at $20 \%$ and $30 \%$ biodiesel concentrations, the number of bacterial colonies on the biofilm increased slightly until the third day. However, the number of bacterial colonies decreased on the fifth day. On the seventh day, the number of colonies increased significantly and dropped dramatically on the final day of immersion. The growth of $S$. marcescens on biofilms is mainly controlled by the concentration of biodiesel in the diesel oil. With the increasing concentrations of biodiesel, the number of bacteria that grew and lived also increased.

\subsection{S. marcescens biofilm morphology}

The observation of biofilm morphology was done by SEM with 5000 times magnification for samples that had been immersed for one, five and ten days. The biofilm morphology formed by the activity of $S$. marcescens for various biodiesel concentrations over ten days can be seen in Figures 2,3, and 4.

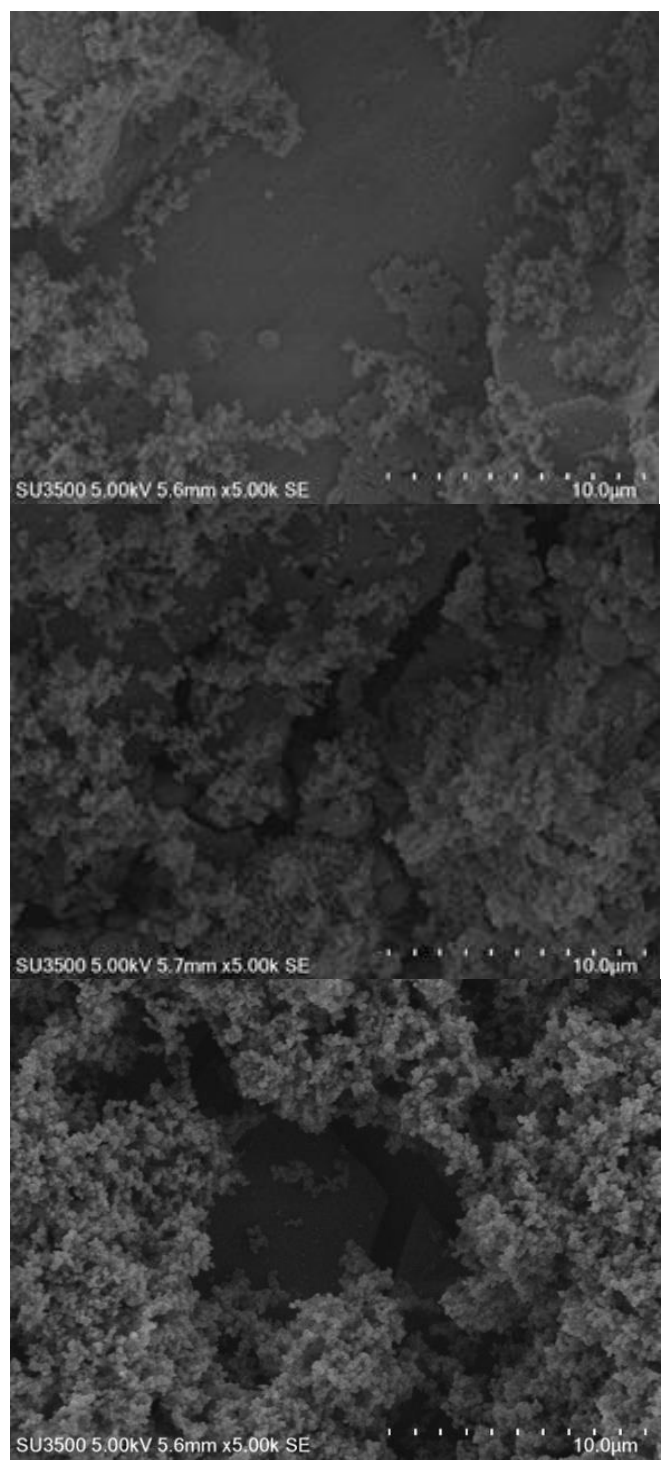

Fig. 2 Biofilm morphologies formed in 1 day at $15 \%$ (top), $20 \%$ (middle) and 30\% (bottom)

On the first day, biofilms begin to appear on the metal surface of all variations of biodiesel. The incidence of cracks seen in Figure 2 indicates that bacteria begin to colonize [14]. After five days of immersion, biofilms formed on $20 \%$ and $30 \%$ biodiesel soaking medium had reached the final stage of maturation and are beginning to enter the final stages. This can be seen due to some biofilms entered lysis processes so the bacteria spread and may colonize to form biofilms elsewhere [6]. On the tenth day, it can be concluded that the bacteria that spread after the final phase form the bonds again with other bacteria on the metal surface. The presence of colonization causes the thickness of biofilm increases [1]. Soaking of metal for ten days also shows the existence of metal damage caused by the activity of $S$. marcescens in the form of pitting. 


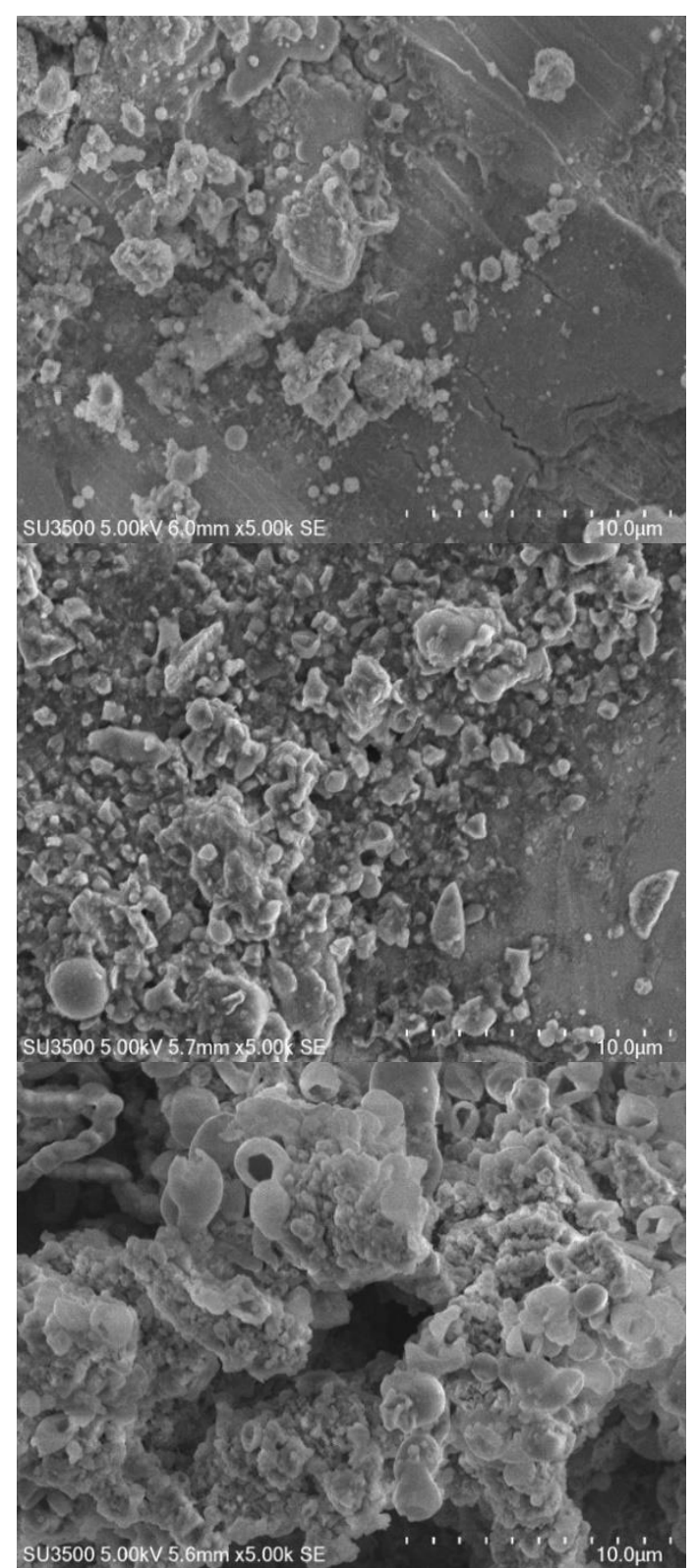

Fig. 3 Biofilm morphologies formed in 5 days at $15 \%$ (top), $20 \%$ (middle) and $30 \%$ (bottom)

\subsection{The loss of metal specimens mass}

By determining the mass loss occurring in the metal by the gravimetric method, the corrosion rate can be calculated. The result of determining the loss of metal mass at various concentrations of biodiesel can be seen in Table 1.

The average value of carbon steel specimens mass loss in the variation of biodiesel concentration by $S$. marcescens bacteria showed no more than $1.2 \%$. The mean mass loss value of the specimens increases proportional to the biodiesel concentration in the medium. The average mass loss values specimens in the variations in of biodiesel concentration is greater compared to the control loss mass values.
Table 1. Weight loss of control and variation specimens during incubation

\begin{tabular}{|c|c|c|}
\hline \multirow{2}{*}{ Variation } & \multicolumn{2}{|c|}{ Average } \\
\cline { 2 - 3 } & $\begin{array}{c}\text { Specimen mass } \\
\text { loss (\%) }\end{array}$ & $\begin{array}{c}\text { Specimen control } \\
\text { mass loss }(\%)\end{array}$ \\
\hline 15 & $0.14 \pm 1 \mathrm{E}-3$ & $0.08 \pm 1 \mathrm{E}-3$ \\
\hline 20 & $0,16 \pm 2 \mathrm{E}-3$ & $0.09 \pm 1 \mathrm{E}-3$ \\
\hline 30 & $0,38 \pm 5 \mathrm{E}-3$ & $0.13 \pm 2 \mathrm{E}-3$ \\
\hline
\end{tabular}

\subsection{Growth of Bacteria in Biofilm}

From Figure, the concentration of biodiesel in diesel fuel influenced the growth of $S$. marcescens in the biofilm. Increasing the concentrations of biodiesel is directly proportional to the number of bacteria that grow and live. This is because $S$. marcescens can utilize biodiesel as a source of nutrients. Also, the properties of biodiesel provide benefits for microorganisms to grow and multiply. Biodiesel is readily degraded in aerobic and anaerobic conditions compared to diesel fuel [15-18]. Stolz et al. [19] and Sendzikiene et al. [20] reported that the fatty acid methyl esters (FAMEs) components comparing to diesel oil components are more rapidly degraded up to four times due to the high percentage of unsaturated esters. Biodiesel made from palm oil containing $40.2 \%$ palmitate $(16: 0)$ and $42.4 \%$ oleate (18:1) make it easier to degrade and useful for microorganisms metabolic process [21]. Reduction for the number of living $S$. marcescens colonies that occur can be caused by the microorganisms converting the unsaturated fatty acids such as palmitate and oleate into components that can poison the microorganism itself namely saturated fatty acids in anaerobic system [16, 22]. Furthermore, supported by the observation of biofilm morphology the lysis process in the biofilm when bacteria reach the final phase, can decrease the number of living colonies.

\subsection{Corrosion Rate}

Determination of the corrosion rate of each variation of biodiesel concentration can be obtained from the mass loss value in the Table 1 .

The corrosion rate is illustrated in Figure 6. During the first three days, the corrosion rate of $S$. marcescens in $15 \%$ biodiesel concentration soaking medium increased slowly to 0.13 mpy. On the fifth day, the corrosion rate declines up to 0.05 mpy. However, there was an increase of corrosion rate up to 0.22 mpy on the tenth day.

A slightly different phenomenon occurs in the variation of $20 \%$ biodiesel concentration. The corrosion rate of $0.13 \mathrm{mpy}$ on the first day decreased periodically to 0.06 mpy until the fifth day. After the fifth day, the increase in corrosion rate that occurs reaches $0.27 \mathrm{mpy}$ at the end of immersion process. 

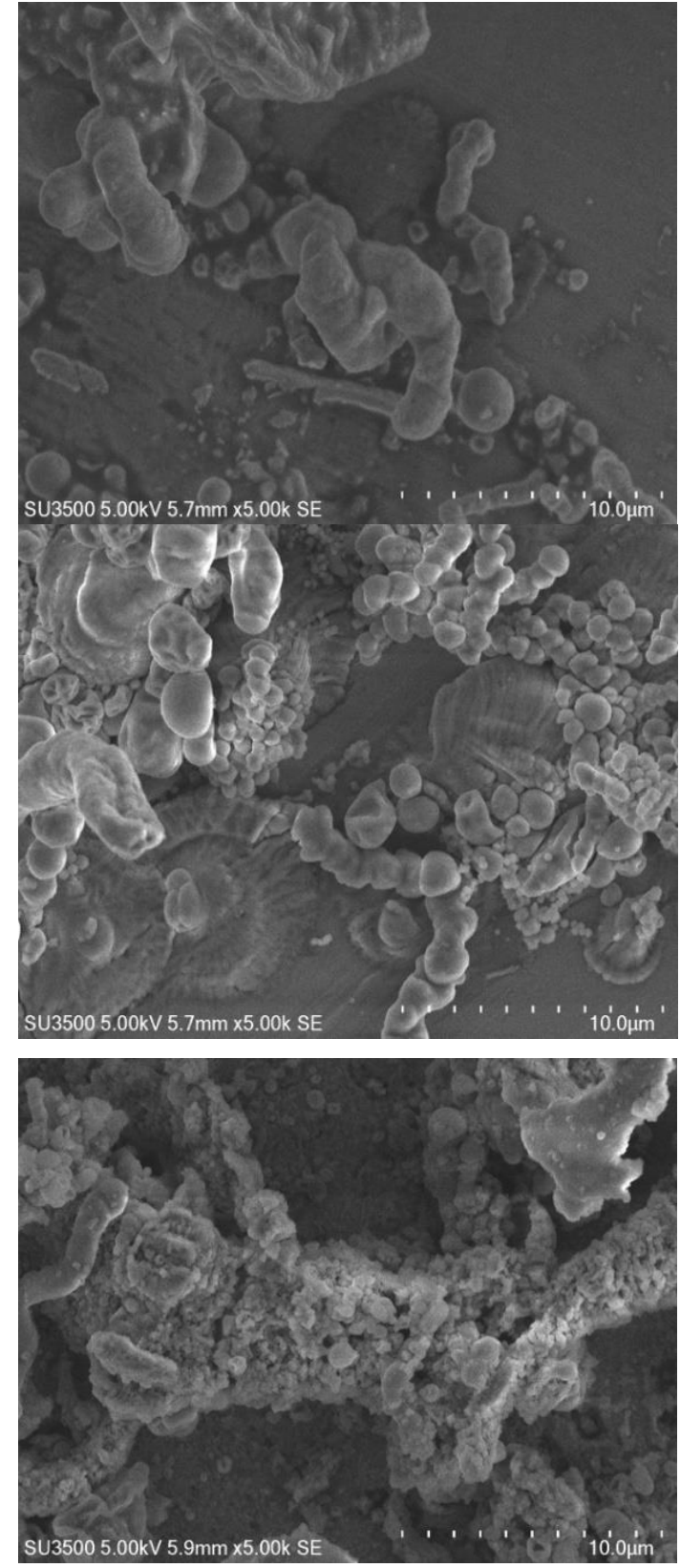

Fig. 4 Biofilm morphologies formed in 10 days at 15\% (top), $20 \%$ (middle) and $30 \%$ (bottom)

In the variation of biodiesel concentration $30 \%$ the corrosion rate increase until the third day. Slowly the rate of corrosion decreased on the fifth day, then increased rapidly reached $0.69 \mathrm{mpy}$ at the end of immersion time.

Increasing in corrosion rate occurring in the first three days for all variations in biodiesel concentration is due to the activity of $S$. marcescens and biofilm formation. The SEM analysis results show that since the first day $S$. marcescens has formed a biofilm on the metal surface.

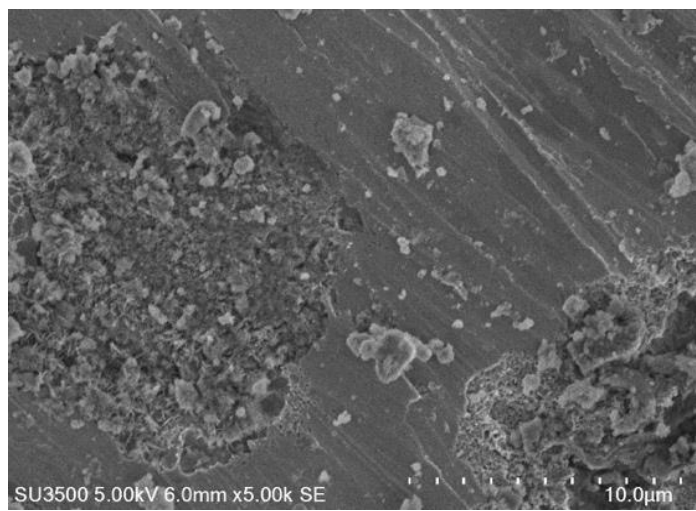

Fig. 5 S. marcescens corrosion attack on carbon steel's surface

The biofilms that formed then matured caused the thickening of the biofilm. After maturation on the fifth day some biofilm for variation of biodiesel concentration $20 \%$ and $30 \%$ experiencing lysis resulting in decreasing the number of $S$. marcescens colonies seen in Figure 1. The biofilm still attached to the metal surface protects the metallic layer from a potentially corrosive environment, resulting in a decrease in corrosion rate [23-25].

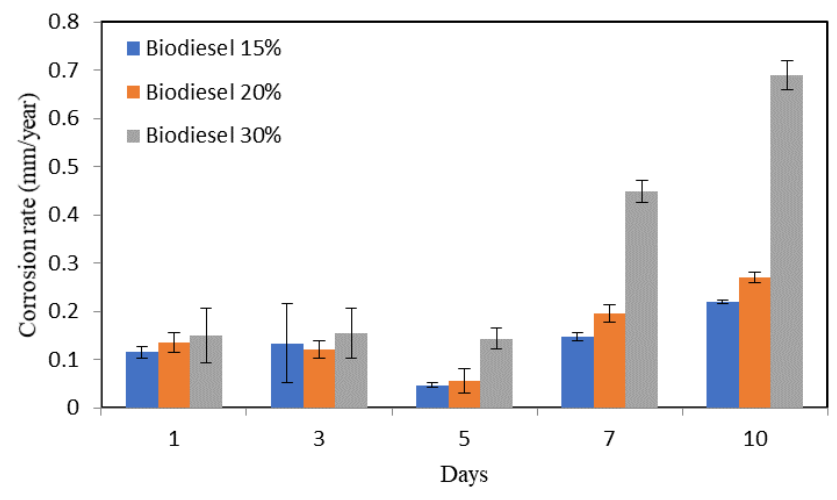

Fig. 6 Carbon steel specimens corrosion rate at various biodiesel concentration

Decreased corrosion rate can also be caused by $S$. marcescens biofilm can minimize the contact of oxygen with the metal surface because the thicker the biofilm formed the oxygen will be difficult to diffuse. Entering the seventh day, the corrosion rate of $S$. marcescens at various concentrations of biodiesel has increased due to the number of colonies that reach the peak point in all variations in the concentration of biodiesel. Many live colonies have the potential to produce many of the metabolites that affect corrosion processes [26-28]. Metabolite products result of biodiesel degradation by microorganisms can decrease the $\mathrm{pH}$ value of the environment because of its acidic nature. In addition to the effect on corrosion, acidic environments can be toxic to microorganisms in biofilms resulting in a decrease in the number of colonies until the final day of immersion [16]. Although the number of living microorganisms decreases, the mass loss of metallic specimens and corrosion rate can be affected by acidic environments. This can be seen from the high corrosion rate for various concentrations of biodiesel on the tenth day. 
The corrosion rate in the mixture of biodiesel and diesel oil and the presence of $S$. marcescens is given in Table 2. Overall the average corrosion rate of controls as well as by $S$. marcescens has the potential to increase along with the addition of biodiesel concentration in diesel oil. In control, the biodiesel concentration in the diesel influences the final $\mathrm{pH}$ of the immersion medium. Increasing in the concentration of biodiesel available in diesel causes a decrease in $\mathrm{pH}$ due to the acidic of biodiesel [29, 30].

Table 2. Average corrosion rate of control and S. marcescens at various biodiesel concentration

\begin{tabular}{|c|c|c|c|}
\hline Variation & $\mathbf{1 5 \%}$ & $\mathbf{2 0 \%}$ & $\mathbf{3 0 \%}$ \\
\hline $\begin{array}{c}\text { Average } \\
\text { corrosion rate } \\
\text { control } \\
\text { (mm/year) }\end{array}$ & $0,085 \pm 0,057$ & $0,087 \pm 0,060$ & $0,130 \pm 0,113$ \\
\hline $\begin{array}{c}\text { Average } \\
\text { corrosion rate } \\
\text { specimen } \\
\text { variation } \\
\text { (mm/year) }\end{array}$ & $0,132 \pm 0,067$ & $0,155 \pm 0,075$ & $0,317 \pm 0,223$ \\
\hline
\end{tabular}

\section{Conclutions}

From the research that has been done can be taken some conclusion that is:

1. Bacterial growth in biofilms was influenced by the concentration of biodiesel in diesel oil.

2. In the absence of microorganisms, the addition of biodiesel to diesel oil can increase the corrosion rate.

3. The corrosion rate of mixed diesel and biodiesel medium increased up to $0,317 \mathrm{~mm} /$ year due to the activity of $S$. marcescens.

\section{Acknowledgments}

The authors would like to express their special thanks to PMDSU Scholarship Ministry of Reseach, Technology and Higher Education, which has provided research funding, Dr. Isdiriayani Nurdin and Dr. Hary Devianto who has provided knowledge, especially regarding theories of corrosion, Chemical Engineering Program at the Institute of Technology Bandung which has provided facilities and infrastructure in the implementation of this research. The staff of Microbiology and Technology, Laboratory of Bioprocess for providing the assistance and doing research are also appreciated.

\section{References}

[1] A. Heyer, F. D'Souza, C. F. L. Morales, G. Ferrari, J. M. C. Mol, and J. H. W. d. Wit, Ocean Eng., 70, 188-200, (2013).

[2] A. J. Wikieł, I. Datsenko, M. Vera, and W. Sand, Bioelectrochemistry, 97, 52-60, (2014).
[3] M. W. Dunne jr, Clin.Microbiol. Rev, 15, 155166, (2002).

[4] M. T. Martinko, Brock Biology of Microorganisms. New York: Pearson Prentice Hall, 2006.

[5] T. S. Rao, in S. Rajagopal, H. A. Jenner, and V. P. Venugopalan, Eds., ed Boston, MA: Springer US, 2012, pp. 95-126.

[6] D. Monroe, PLoS Biology 5, 307, (2007).

[7] C. A. H. Von Wolzogen Kuehr and L. S. van der Vlugt, (2006).

[8] X. Y. Zhu, J. Lubeck, and J. J. Kilbane, App. Environ. Microbiol., 69, 5354-5363, (2003).

[9] N. Muthukumar, S. Mohanan, S. Maruthamuthu, P. Subramanian, N. Palaniswamy, and M. Raghavan, Electrochem Commun 5, 412-426, (2003).

[10] A. Rajasekar, S. Maruthamuthu, N. Muthukumar, S. Mohanan, P. Subramanian, and N. Palaniswamy, Corros. Sci., 47, 257-271, (2005).

[11] J. Jan-Roblero, A. Posadas, F. Zavala-Diaz de la Serna, and R. Garcia, World J Microbiol Biotechnol 24, 1775-1784, (2008).

[12] P. Wongsa, A. Tanaka M Fau - Ueno, M. Ueno A Fau - Hasanuzzaman, I. Hasanuzzaman M Fau - Yumoto, H. Yumoto I Fau - Okuyama, and H. Okuyama, 20050207 DCOM20050303.

[13] A. Rajasekar, T. G. Babu, S. T. K. Pandian, S. Maruthamuthu, N. Palaniswamy, and A. Rajendran, J. Ind. Microbiol. Biotechnol., 34, 589-598, (2007).

[14] T. Lie, J. Periodontal Res., 13, 391-409, (1978).

[15] X. Zhang, C. Peterson, D. Reece, R. Haws, and G. Moller, Trans. ASAE, 41, 1423-1430, (1998).

[16] J. S. Lee, R. I. Ray, and B. J. Little, DTIC Document, (2009).

[17] D. F. Aktas, J. S. Lee, B. J. Little, K. E. Duncan, B. M. Perez-Ibarra, and J. M. Suflita, Int. Biodeterior. Biodegrad., 81, 114-126, (2013).

[18] J. S. Lee, R. I. Ray, B. J. Little, K. E. Duncan, A. L. Oldham, I. A. Davidova, et al., Biofouling, 28, 465-478, (2012).

[19] J. F. Stolz, P. Follis, G. Floro, R. Donofrio, J. Buzzelli, and W. M. Griffin, (1995).

[20] E. Sendzikienea, V. Makarevicienea, P. Janulisa, and D. Makareviciuteb, Eur. J. Lipid Sci. Technol., 109, 493-497, (2007).

[21] R. El-Araby, A. Amin, A. K. El Morsi, N. N. El-Ibiari, and G. I. El-Diwani, Egyptian Journal of Petroleum, (2017).

[22] D. Z. Sousa, H. Smidt, M. M. Alves, and A. J. Stams, FEMS Microbiol. Ecol, 68, 257-272, (2009).

[23] S. G. G. d. Saravia, M. F. L. d. Mele, and H. A. Videla, Corros. Sci., 46, 302-306, (1990).

[24] Z. Lewandowski, W. Dickinson, and W. Lee, Water Sci Technol, 36, 295-302, (1997). 
[25] J. D. Gu, M. Roman, T. Esselman, and R. Mitchell, Int. Biodeterior. Biodegrad., 41, 2533, (1998).

[26] J. W. Sutherland, Trends Microbiol, 9, 222-227, (2001).

[27] J. S. Lee, R. I. Ray, and B. J. Little, Biofouling, 26, 623-35, Aug (2010).

[28] T. H. Ching, B. A. Yoza, R. Wang, S. Masutani, S. Donachie, L. Hihara, et al., Int. Biodeterior. Biodegrad., 108, 122-126, (2016).

[29] M. A. Fazal, A. S. M. A. Haseeb, and H. H. Masjuki, Corros. Sci., 67, 50-59, (2013).

[30] T. Eryilmaz and M. K. Yesilyurt, Renewable Energy, 95, 233-247, (2016). 